\title{
Meditation on a Daily Basis Makes Wise without Violence
}

\author{
S Punthawanunt ${ }^{1}$ and P Yupapin ${ }^{2,3 *}$ \\ ${ }^{1}$ Multidisciplinary Research Center, Faculty of Science and Technology, Kasem Bundit University, Thailand \\ ${ }^{2}$ Computational Optics Research Group, Advanced Institute of Materials Science, Ton Duc Thang University, District 7, Ho Chi Minh City, Vietnam \\ ${ }^{3}$ Faculty of Electrical \& Electronics Engineering, Ton Duc Thang University, District 7, Ho Chi Minh City, Vietnam
}

Submission: December 09, 2017; Published: March 09, 2018

*Corresponding author: Preecha Yupapin, Department for Management of Science and Technology Development, Faculty of Electrical \& Electronics Engineering, Ton Duc Thang University, District 7, Ho Chi Minh City, Vietnam, Email: preecha.yupapin@tdt.edu.vn

\begin{abstract}
Human brain performance can be increased by reducing craving (noise) instead of increasing brain signal, from which the brain performance is given by the ratio between brain signal and craving. The brain performance can be changed by the change in craving, which can be larger or smaller, where the change in brain signal is not required. Such a requirement can be obtained by the practical way known as a meditation, in which the spirit signal can lead to be a single peak with the certain energy states. By using the Four Mindfulness Foundation, the meditation on a daily basis can be achieved, in which the wisdom without violence can be obtained.
\end{abstract}

Keywords: Buddhism philosophy; Daily life meditation; Mindfulness; Meditation; Spiritual science

\section{Introduction}

Meditation has been recognized as the useful technique of mind concentration for a long time, in which the single configured mind is the required target. The important history was recorded when the Lord Buddha had announced the Tripitaka thousand years ago [1-2]. Since then the meditation technique has been investigated in both theory and experiment [3-8], wherein principle there are two types of meditation, which are the elementary and deeply meditations. Principally, there are two types of both levels of meditations that can be named by force meditation and auto(random) meditations, in which the force meditation is focused on a single target and finally the single mind is achieved, while the auto-meditation is achieved by moving mind within the body, which is employed by the Lord Buddha principle known as "Four Mindfulness Foundation" $[1,9]$, where the popular one is the body consideration, with the free mind move within the body, where finally, the mindfulness is achieved, in addition, the single mind is also automatic achieved without any forcing concentration. The latter method can actually be happened anytime, which can say the everyday life meditation, which can be done when we are working or in any situation, for the instant, sitting, lying down, walking, which will be the benefit to human life in any situation.
In scientific interpretation, there various results are obtained by the meditation [10-15], which are increases immune function, decreases pain, decreases inflammation at the cellular level, increases positive emotion, decreases depression, decreases anxiety, decreases stress, increases social connection and emotional intelligence, makes you more compassionate, feel less lonely, improves ability to regulate emotions, improves your ability to introspect, increases grey matter, increases volume in areas related to emotion regulation, positive emotions and selfcontrol, increases cortical thickness in areas related to paying attention, increases your focus \& attention, improves your ability to multitask, improves memory, improves your ability to be creative \& think outside the box. In applications, apart from the high level of meditation known as Vipassana meditation [1], the use of meditation for various fields has been found [16-27], for the instant, for health treatment, psychology investigation, medical diagnosis, etc. In this paper, the brain signal is modeled to form the relationship between the meditation level and brain signal forms, in which the meditation related phenomena can be clearly described, which may help the meditation practitioner achieve successfully, where in addition, such a technique can be used in everyday life, where the world violence can be increased, while the working performance can also be increased. 


\section{Principle}

Given the brain signal oscillation in brain and linking to the whole body is formed by a soliton pulse, which is a synchronized pumping by the heart pumping cycle, which can be manipulated by a laser and obtained by the soliton pulse, which can be expressed by $[28,29]$.

$$
\begin{aligned}
& \psi(t)=\bar{A} \tanh \left[\frac{T}{T_{0}}\right] \exp \left[\left(\frac{z}{2 L_{D}}\right)+i \varphi(t)\right]=A e^{-i \frac{E}{\hbar} t} \\
& \text { Given } A=\bar{A} \tanh \left[\frac{T}{T_{0}}\right] \exp \left(\frac{z}{2 L_{D}}\right)
\end{aligned}
$$

Where $\mathrm{E}=\mathrm{nh} v ; \mathrm{n}=1,2,3 \ldots . .$, and

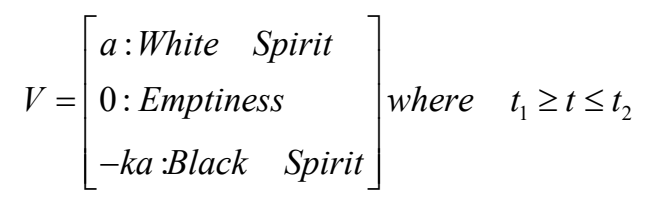

Where the potential function $\mathrm{V}$ is the spirit transient energy introduced by the personal passion or craving, the spirit signal is formed by a soliton pulse at the same time with the origin of time. In which $\mathrm{A}$ and $\mathrm{z}$ are the spirit signal amplitude and the circulation distance within the being brain, respectively, where the spirit signal is formed by the soliton pulse, therefore, the other parameters are the same as the soliton parameters in reference [29]. The amplitude of optical fields is represented by $A_{i}$ and $A_{s}$ respectively. The propagation distance is demonstrated by z. The propagation time for soliton pulse moving with a group velocity in a frame is $T=t-\beta_{1} \times z$. Here, soliton phase shift time is $\mathrm{t}$, and $\omega_{0}$ is the frequency shift of the soliton. $L_{d}=T_{0}^{2} /\left|\beta_{2}\right|$ represents the dispersion length of the soliton pulse, where $T_{0}$ shows soliton pulse propagation time at the initial input. The coefficients of the linear and the second order terms of the Taylor's expansion of the propagation constant are $\beta_{1}$ and $\beta_{2}$ , respectively. For the soliton pulse in the micro ring device, a balance should be achieved between the dispersion length $\left(L_{d}\right.$ ) and the nonlinear length $L_{N L}=1 / \Gamma \varphi_{N L}$, where $\Gamma=n_{2} \mathrm{~K}_{0}$, is the length scale over which dispersive or nonlinear effects alter the beam diameter. For a soliton pulse, there is a balance between dispersion and nonlinear lengths, hence $L_{d}=L_{N L}$ [29].

\section{Scientific Interpretation}

In this article, there are two types of meditations, which are the (i) forced and (ii) the auto-meditations discussed and the practical details explained. Spirit energy is split into two parts, which are the orthogonal basis known entangled pair. One is localized within the body (form), the other is called the abstract and localized in the Hilbert space, is represented by the complex conjugate term. The link between form and abstract spirits is formed by the entangled part. In the meditation, the maximum resultant vector of them can be obtained, when one is the maximum, the other is minimum, which can be formed inside or outside the body. However, the one inside the body is recommended, which will be described later. When the single spirit peak signal is formed, the phenomena called "Cerenkov radiation" can be seen due to the speed of spirit (photon) is greater than the spirit group velocity, in which the bright light called "aura" can be seen or enlighten. In such a situation, the spirit is in the stopped in time condition, in which the oscillation in time is approached zero, which is gone under the cold light spreading over the body. Eventually, the spirit is cut-off from the body, which is introduced by the non-existence of five aggregates by Trinity consideration. The spirit now becomes a point of a unit vector with very high density in the body center, which is called a cold body state, from which the spirit is in the adiabatic system without the internal energy as well, the body is operated by the minimum energy called harmonic oscillator energy. The term no time means the spirit can travel in time freely In the meditation, the level of energy can be distinguished by mean of quantum physics, $E=n h v$, where $n=1,2,3 \ldots$, where the initial state of human spirit energy is $n=2$, which is called the Rabi oscillation. In principle, the state of spirit energy can be finer and finer, from $n=2,3,4$, to $n \rightarrow \infty$, for example, when the deep meditation (Vipassana or Insight) is done, the energy level is finer and finer, which may be approached $n \rightarrow \infty$. In Figure 1 , the spirit energy is divided into two parts, which are in the form of the entangled vector components, where $\psi$ is a form, while $\psi^{*}$ is abstract. The joint event is the entangled occurrence, which may often come across by the dream, in which the occurrence in the dream will be blurred after wakening up.

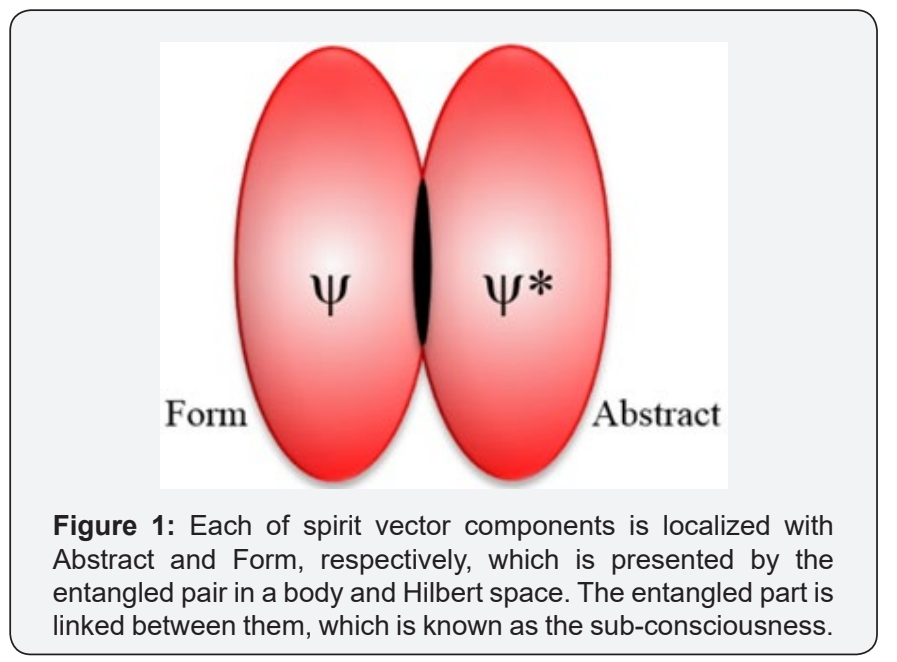

In Figure 2, the single mind target is done by the outside body target, from which the strong single mind can be obtained, which is very high energy (power). However, the single mind with a very narrow width or short time without any control arrangement can introduce the very high frequency, from which the very high energy in terms of the Plank's constant occurs, which leads to the uncertainty product of the black hole energy, which is the dark side spirit (mind) energy, which means the energy is approached infinity in the dark side, when time is approached zero, i.e. no time. To solve this problem, the automeditation is recommended, where the body consideration 
in the FMF can reduce the spirit energy, which is bounded by the body, from which both mindfulness and concentration (meditation) can be achieved together. The wisdom is formed by the Vipassana meditation, while the craving is filtered to be the small amount by the Eight Noble Truths, from which the high intelligent is established. The certain craving amount is bounded by the Trinity without any violence.

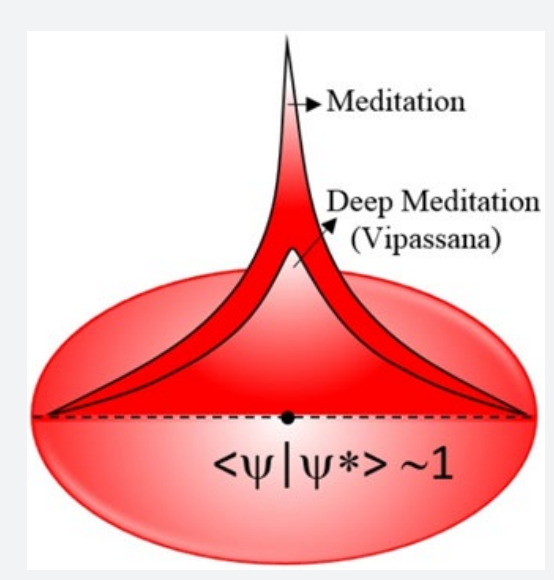

Figure 2: Elementary and deeply meditation description, where the stopping brain(spirit) signals can generate the cold body system, while the spirit energy is localized under the adiabatic process, from which the internal energy is approached zero, the spirit signal is functioned by the quantum harmonic oscillator, $E=\hbar \omega$.

\section{Conclusion}

We have shown that the brain signals can be modeled by using the soliton pulse, which is existed and generated by the energy oscillation in time. The relationship between the brain signals and meditation is interpreted, which may be useful for the investigation such as neuroscience, meditation level, mind etc. The elementary and deep meditations can lead to being delightful and emptiness. By using the FMF method, the nonexist and cut-off of five aggregates are introduced, where finally, the emptiness occur, the form vanishes, while the abstract remains in the origin, i.e. neutral world, which is lined with the universe and black hole [2], which is satisfied the concept of energy conservation between black hole and universe.

\section{References}

1. Edelglass W, Garfield JL (2009) Buddhist Philosophy: Essential Readings. Oxford University Press, New York, USA.

2. Phunthawanunt S, Yupapin P (2017) Quantum networks of wisdom and mindfulness for practitioners. International Journal of Philosophy Study 5: 1-7.

3. Phunthawanunt S, Yupapin PP (2014) Science of meditation and therapy. Journal of Hamonized Researches in Applied Science 2(3): 174-177.

4. Barrett B, Hayney MS, Muller D, Rakel D, Ward A, et al. (2012) Meditation or exercise for preventing acute respiratory infection: a randomized controlled trial. Ann Fam Med 10: 337-346.

5. Brewer JA, Mallik S, Babuscio TA, Nich C, Johnson HE, et al. (2011)
Mindfulness training for smoking cessation: results from a randomized controlled trial. Drug Alcohol Depend 119(1-2): 72- 80.

6. Brook RD, Appel RJ, Rubenfire M, Ogedegbe G, Bisognano JD, et al. (2013) Beyond medications and diet: alternative approaches to lowering blood pressure: a scientific statement from the American Heart Association. Hypertension 61(6): 1360-1383.

7. Carim Todd L, Mitchell SH, Oken BS (2013) Mind-body Practices: An alternative, drug-free treatment for smoking cessation? A systematic review of the literature. Drug Alcohol Depend 132(3): 399-410.

8. Yupapin PP, Punthawanunt S (2016) Quantum meditation: the selfspirit projection. International Journal of Philosophy Study 4: 1-5.

9. Yupapin PP (2015) Contemplation and perception energy transition states. Int J Scien World 3(2): 223-226.

10. Wendt A (2015) Quantum mind and social science.

11. Greeson JM, Webber DM, Smoski MJ, Brantley JG, Ekblad AG, et al. (2011) Changes in spirituality partly explain health-related quality of life outcomes after Mindfulness-Based Stress Reduction. J Behav Med 34(6): 508-518.

12. Gaylord SA, Palsson OS, Garland EL, Faurot KR, Coble RS, et al. (2011) Mindfulness training reduces the severity of irritable bowel syndrome in women: results of a randomized controlled trial. Am J Gastroenterol 106(9): 1678-1688.

13. Goldstein CM,Josephson R, Xie S, HughesJW (2012) Currentperspectives on the use of meditation to reduce blood pressure. International Journal of Hypertension 2012: 11.

14. Goyal M, Singh S, Sibinga EM, Gould NF, Rowland Seymour A, et al. (2014) Meditation programs for psychological stress and well-being: a systematic review and meta-analysis. JAMA Intern Med 174(3): 357368.

15. Jedel S, Hoffman A, Merriman P, Swanson B, Voigt R, et al. (2014) A randomized controlled trial of mindfulness-based stress reduction to prevent flare-up in patients with inactive ulcerative colitis. Digestion 89(2): 142-155.

16. Lakhan SE, Schofield KL (2013) Mindfulness-based therapies in the treatment of somatization disorders: a systematic review and metaanalysis. PLoS One 8(8): e71834.

17. Luders E (2013) Exploring age-related brain degeneration in meditation practitioners. Ann N Y Acad Sci 1307: 82-88.

18. Luders E, Kurth F, Mayer EA, Toga AW, Narr KL, et al. (2012) The unique brain anatomy of meditation practitioners: alterations in cortical gyrification. Front Hum Neurosci 6: 36.

19. Nidich SI, Rainforth MV, Haaga DA, Hagelin J, Salerno JW, et al. (2009) A randomized controlled trial on effects of the transcendental meditation program on blood pressure, psychological distress, and coping in young adults. Am J Hypertens 22(12): 1326-1331.

20. Morgan N, Irwin MR, Chung M, Wang C (2014) The effects of mindbody therapies on the immune system: meta-analysis. PLOS One 9(7): e100903.

21. Ong JC, Manber R, Segal Z, Xia Y, Shapiro S, et al. (2014) A randomized controlled trial of mindfulness meditation for chronic insomnia. Sleep 37(9): 1553-1563.

22. Reiner K, Tibi L, Lipsitz JD (2013) Do mindfulness-based interventions reduce pain intensity? A critical review of the literature. Pain Med 14(2): 230-242.

23. Rosenkranz M, Davidson RJ, MacCoon D, Sheridan JF, Kalin NH, et al. (2013) A comparison of mindfulness-based stress reduction and an active control in modulation of neurogenic inflammation. Brain Behav Immun 27(1): 174-184. 
24. Rubia K (2009) The neurobiology of meditation and its clinical effectiveness in psychiatric disorders. Biol Psychol 82(1): 1-11.

25. Tang YY, Tang R, Posner MI (2013) Brief meditation training induces smoking reduction. Proc Natl Acad Sci U S A 110(34): 13971-13975.

26. Westbrook C, Creswell JD, Tabibnia G, Julson E, Kober H, et al. (2013) Mindful attention reduces neural and self-reported cue-induced craving in smokers. Soc Cogn Affect Neurosci 8(1): 73-84.

27. Zeidan F, Adler Neal AL, Wells RE, Stagnaro E, May LM, et al. (2016)
Mindfulness-meditation-based pain relief is not mediated by endogenous opioids. J Neurosci 36(11): 3391-3397.

28. Noorden AFA, Chaudhary K, Bahadoran M, Aziz MS, Jalil MA, et al. (2015) Rabi oscillation generation in the microring resonator system with double-series ring resonators. Optoelectronics Letters 11(5): 342-347.

29. Agrawal GP (2007) Nonlinear Fiber Optics. ( $4^{\text {th }}$ edn), Academic Press, New York, USA.

\section{Your next submission with Juniper Publishers will reach you the below assets}

- Quality Editorial service

- Swift Peer Review

- Reprints availability

- E-prints Service

- Manuscript Podcast for convenient understanding

- Global attainment for your research

- Manuscript accessibility in different formats

( Pdf, E-pub, Full Text, Audio)

- Unceasing customer service

Track the below URL for one-step submission https://juniperpublishers.com/online-submission.php 